\title{
Parenting Style as Context: An Integrative Model
}

\author{
Nancy Darling and Laurence Steinberg
}

\begin{abstract}
Despite broad consensus about the effects of parenting practices on child development, many questions about the construct parenting style remain unanswered. Particularly pressing issues are the variability in the effects of parenting style as a function of the child's cultural background, the processes through which parenting style influences the child's development, and the operationalization of parenting style. Drawing on historical review, the authors present a model that integrates two traditions in socialization research, the study of specific parenting practices and the study of global parent characteristics. They propose that parenting style is best conceptualized as a context that moderates the influence of specific parenting practices on the child. It is argued that only by maintaining the distinction between parenting style and parenting practice can researchers address questions concerning socialization processes.
\end{abstract}

During the past 25 years, research based on Baumrind's conceptualization of parenting style has produced a remarkably consistent picture of the type of parenting conducive to the successful socialization of children into the dominant culture of the United States. Authoritativeness-a constellation of parent attributes that includes emotional support, high standards, appropriate autonomy granting, and clear, bidirectional communication-has been shown to help children and adolescents develop an instrumental competence characterized by the balancing of societal and individual needs and responsibilities. Among the indicators of instrumental competence are responsible independence, cooperation with adults and peers, psychosocial maturity, and academic success (for reviews, see Baumrind, 1989, 1991a).

This work on authoritativeness and its beneficial effects builds on half a century of research on parenting and parenting style. Yet, despite some impressive consistencies in the socialization literature, important questions remain unanswered. As researchers have expanded beyond samples of White, predominantly middle-class families, it has become increasingly clear that the influence of authoritativeness, as well as other styles of parenting, varies depending on the social milieu in which the family is embedded. For example, Baumrind (1972) reported that authoritarian parenting, which is associated with fearful, timid behavior and behavioral compliance among EuropeanAmerican children, is associated with assertiveness among African-American girls. Furthermore, recent studies in which the effects of authoritativeness have been compared across ethnic groups have consistently shown that authoritative parenting is most strongly associated with academic achievement among

Nancy Darling and Laurence Steinberg, Department of Psychology, Temple University.

Work on this article was supported by grants from the Lilly Endowment and the William T. Grant Foundation. Our thanks to Diana Baumrind, Marsha Weinraub, and several anonymous reviewers for their thoughtful comments.

Correspondence concerning this article should be addressed to Laurence Steinberg, Department of Psychology, Temple University, Philadelphia, Pennsylvania 19122.
European-American adolescents and is least effective in influencing the academic achievement of Asian- and AfricanAmerican youths (Dornbusch, Ritter, Leiderman, Roberts, \& Fraleigh, 1987; Steinberg, Mounts, Lamborn, \& Dornbusch, 1991).

How can such variability be explained? Are the processes through which authoritativeness enhances development undermined by other processes operating in particular cultural milieus (e.g., within the child's peer group)? Or is there something fundamentally different about the processes that occur within authoritative families in different milieus that results in different consequences for the child? ${ }^{1}$ For example, are the goals toward which authoritative parents try to socialize their children the same in African- and European-American homes? Alternatively, perhaps the goals African- and European-American authoritative parents hold are the same, but the methods they use to help children attain these goals differ.

Although much has been written in theory about the processes through which parenting style may influence child development (for excellent discussions, see Baumrind, 1971a, 1983; Lewis, 1981), in actuality we have a very limited empirical basis on which to assess alternative hypotheses about the conditions under which the same parenting style may differentially affect children's development. One clear consequence of this absence is our lack of understanding of ethnic differences in the impact of authoritativeness on children's development. Another is that there is no empirical basis on which to draw conclusions about how the appropriateness of different parenting styles may vary depending on the child's developmental stage (e.g., Steinberg, Elmen, \& Mounts, 1989).

\footnotetext{
'Although some writers have treated parenting style as if it were a developmental process, we disagree. A developmental process is defined by interactions between the developing person and his or her environment. Parenting style is a characteristic of the parent (i.e., it is a feature of the child's social environment), independent of characteristics of the developing person. In contrast, the extent and nature of the child's identification with parents are examples of developmental processes, because identification inherently involves both the child and the object of the identification.
} 
In this article, we argue that to understand the processes through which parenting style influences child development, one must disentangle three different aspects of parenting: the goals toward which socialization is directed; the parenting practices used by parents to help children reach those goals; and the parenting style, or emotional climate, within which socialization occurs. We argue that parenting style is most usefully conceptualized as a characteristic of the parent that alters the efficacy of the parent's socialization efforts by moderating the effectiveness of particular practices and by changing the child's openness to socialization.

To make this argument, we review the historical development of the parenting style construct, paying careful attention to the processes through which parenting style has been thought to influence child outcomes. Key to this discussion is our exegesis of the historical tension between researchers interested in the developmental consequences of particular parenting practices and those interested in more global parenting characteristics, or parenting style. Drawing on this review, we develop a model of parenting that encompasses parenting goals, practices, and style, and we discuss how this model facilitates addressing extant issues in socialization research.

\section{Historical Change in the Conceptualization of Parenting Style}

\section{Emotional Relationships and Parenting Behaviors}

The model we offer defines parenting style as a constellation of attitudes toward the child that are communicated to the child and that, taken together, create an emotional climate in which the parent's behaviors are expressed. These behaviors include both the specific, goal-directed behaviors through which parents perform their parental duties (to be referred to as parenting practices) and non-goal-directed parental behaviors, such as gestures, changes in tone of voice, or the spontaneous expression of emotion.

This definition of parenting style is consistent with some of the earliest research on socialization, conducted during the 3 rd and 4th decades of the 20th century. Interest in the influence of parents' behavior on child development was a natural outgrowth of both behaviorist and Freudian theory. Child behaviorists were interested in how the patterning of reinforcement in the near environment shaped development. Freudian theorists, in contrast, argued that the basic determinants of development were biological and inevitably in conflict with parental desires and societal requirements. The interaction between the child's libidinal needs and the family environment was presumed to determine individual differences in children's development. Then, as now, two questions dominated socialization research: What are the modal patterns of child rearing? What are the developmental consequences of different child rearing patterns?

Although there was general agreement that parenting practices influence child development, documenting the influence of specific practices proved elusive. Early socialization researchers recognized that individual parenting behaviors were part of a milieu of many other behaviors and, therefore, that the influence of an individual behavior could not be easily disaggregated. As one influential group noted,

It is possible for the child to take a great deal of rather crude cuffing and spanking and still feel so fully the affection and warmth of the parents' concern that no harm results. And it is possible for parents to do the technically correct thing with so little apparent affection that even their kind and patient words leave the child cold as well as confused and resentful. (Greenberg and Others of the Staff of the Child Study Association of America, 1936, quoted by Symonds, 1939, p. 153)

Parenting style developed initially as a heuristic device to describe the parenting milieu. To the extent that this milieu was accurately captured by measures of parenting style, analyses using the construct were presumed to be more predictive of child attributes than analyses based on specific parenting practices, because the influence of any particular parenting practice on child development would easily be lost among the complexity of other parental attributes (Baldwin, 1948; Orlansky, 1949; Symonds, 1939). Initial qualitative and later quantitative efforts to assess parenting style focused on three particular components: the emotional relationship between the parent and child, the parents' practices and behaviors, and the parents' belief systems. Because researchers from different theoretical perspectives emphasized different processes through which parents influence their children, their writings stressed different components of style.

The psychodynamic model. Socialization researchers who worked from a psychodynamic perspective concentrated their efforts on the emotional relationship between the parent and child and its influence on the child's psychosexual, psychosocial, and personality development. Like other theories of socialization offered during this historical era, their models were strictly unidirectional. These theorists argued that individual differences in the emotional relationships between parents and children must necessarily result from differences in parental attributes, and many researchers focused on attitudes as the attributes of importance. For example, after reviewing research on the influence of a broad range of parenting practices on infant personality development and concluding that there was essentially no consistent relationship between any specific parental practice and child outcomes, Orlansky (1949) wrote,

We lean to the belief that a specific discipline does not exert a specific invariant psychological influence upon the child and that its effect can be gauged only from a study of the parental attitudes associated with its administration. (pp. 7-8)

Because attitudes help determine both parental practices and the more subtle behaviors that give those practices meaning, many investigators who worked in this tradition reasoned that assessing parental attitudes would capture the emotional tenor of the family milieu that determined the parent-child relationship and influenced the child's development (Baldwin, 1948; Orlansky, 1949; Schaefer, 1959; Symonds, 1939). This shift in emphasis from parents' behaviors to their attitudes posed a problem for researchers, however. Behavior is determined and made meaningful by attitudes, but attitudes are expressed through behavior. As Symonds (1939) wrote, "Eventually the child's emotional security does go back to the parents' feelings and attitudes, needs and purposes, but only as they are openly 
expressed to him in word and action" (p. 154). In essence, although attitudes were deemed to be more important than behaviors per se, there was no means of studying the former without measuring the latter.

Researchers who focused on the emotional processes underlying parenting style tried to bridge this gap between parental attitudes and the specific behaviors they were thought to engender by aggregating behavior at what Schaefer (1959) called a "molar" level. Rather than using individual practices to define parenting style, particular practices were grouped conceptually into broader categories on the basis of their potential to alter emotional processes (Baldwin, 1948; Orlansky, 1949; Schaefer \& Bell, 1958; Symonds, 1939). These molar attributes included, among others, autonomy granting, ignoring, punitiveness, perception of the child as a burden, strictness, use of fear to control, and expressions of affection (Schaefer, 1959, 1965). Schaefer used circumplex modeling to organize these attributes into a typology of parenting style believed to capture both attitudes and practice.

The learning model. Researchers who approached parenting style from behaviorist and social learning perspectives at the time also sought to categorize parenting style according to parental behaviors, but they focused their efforts on parental practices rather than attitudes. Because differences in children's development were thought to reflect differences in the learning environment to which they had been exposed, measures of parenting style were designed to capture the patterning of behaviors that defined these environments (e.g., Sears, Maccoby, \& Levin, 1957; Whiting \& Child, 1953). In these approaches, factor analysis might be used to identify control as a behavioral attribute underlying the pattern of correlations among such practices as a parent's use of physical punishment, tolerance of masturbation, sanctions against aggression, failure to enforce rules, and rules for use of common living areas. Parenting style was used as a sort of shorthand to summarize the results of the many analyses performed on specific parenting practices, rather than reified as an entity unto itself, as it was by the analytically oriented theorists.

Dimensions of style. The utility of parenting style as a heuristic device is reflected in the similarity of the qualities used to describe it by researchers who worked from different theoretical vantage points, were interested in different developmental outcomes, and focused on different socialization processes. Just as early theories of parenting differed in their emphasis on control (Watson, 1928) and nurturance (Freud, 1933; Rogers, 1960), so did the dimensions used to describe parenting style in early empirical research on socialization. For Symonds (1939), these dimensions included acceptance/rejection and dominance/submission; for Baldwin (1955), emotional warmth/hostility and detachment/involvement; for Schaefer (1959), love/ hostility and autonomy/control; for Sears et al. (1957), warmth and permissiveness/strictness; and for Becker (1964), warmth/ hostility and restrictiveness/permissiveness. In retrospect, the similarity of the underlying dimensions proposed by these different researchers is remarkable.

In addition to this basic agreement about the underlying organizational structure of parenting style, a consensus began to emerge about the association between child outcomes and parenting. Model children-whom Symonds (1939) described as "socialized, cooperative, friendly, loyal, emotionally stable, and cheerful . . honest, straightforward, and dependable . . . good citizens and good scholars" (p. 75) and whom Baumrind (1970) would later call "instrumentally competent"-were the products of homes in which parents behaved in a particular manner. These parents were warm, established clear, rational guidelines while allowing the child autonomy within those boundaries, and clearly communicated both their expectations and the reasons behind them (Baldwin, 1948, 1955; Sears et al., 1957; Symonds, 1939).

The importance of both the affective and instrumental processes emphasized by psychodynamic and learning theorists, respectively, is evident in these findings. Both Sears's (1957) melding of the Freudian concept of identification with learning theory and the limited usefulness of direct measures of parents' attitudes in predicting child outcomes without parenting practices to mediate the process (for a review, see Becker, 1964) suggested the importance of examining affective and instrumental processes within a single model.

Psychodynamic and social learning theorists both agreed that the instrumental and interpersonal goals toward which parents socialize their children and parents' beliefs about parenting and the nature of children were critical determinants of parents' practices, but psychologists rarely measured these ostensibly critical antecedents. For sociologists, however, value transmission and the role families played in maintaining the social order were important elements of functionalist and structural-functionalist theories. Thus, although psychologists paid scant attention to parents' beliefs, the determinants and significance of these belief systems received attention from social scientists interested in the influence of the broader social context on parenting, most importantly, Parsons and Bales (1955), Kohn (1969), and Bronfenbrenner (1958, 1961a, 1961b).

An important gap between the study of socialization goals and the study of socialization techniques remained for some time. It was not until Baumrind (1966), however, that a theoretical model emerged that incorporated the emotional and behavioral processes that underlay earlier models of socialization into a conceptualization of parenting style that was anchored in an emphasis on parents' belief systems. This model would profoundly alter subsequent thinking about parenting style.

\section{Belief Systems and Ecological Niches: Baumrind's Typology}

For Baumrind, socializing child to conform to the necessary demands of others while maintaining a sense of personal integrity was the key element of the parental role. Her early research focused on the influence of normal variation in the patterning of parental authority on early childhood development. She began by articulating and enlarging the concept of parental control. Previously, control had been variously defined as strictness, use of physical punishment, consistency of punishment, use of explanations, and so on (for a review, see Baumrind, 1966). In contrast, Baumrind argued that parents' willingness to socialize their child is conceptually distinct from parental restrictiveness and used the concept of parental control to refer to parents' attempts to integrate the child into the family and society by demanding behavioral compliance. 
In Baumrind's (1968) conceptualization of parenting style, parents' values and the beliefs they hold about their roles as parents and the nature of children help define naturally occurring patterns of affect, practices, and values. This can be seen in her description of the prototypic authoritative parent:

She encourages verbal give and take, and shares with the child the reasoning behind her policy. She values both expressive and instrumental attributes, both autonomous self-will and disciplined conformity. Therefore, she exerts firm control at points of parentchild divergence, but does not hem the child in with restrictions. She recognizes her own special rights as an adult, but also the child's individual interests and special ways. The authoritative parent affirms the child's present qualities, but also sets standards for future conduct. She uses reason as well as power to achieve her objectives. She does not base her decisions on group consensus or the individual child's desires; but also does not regard herself as infallible or divinely inspired. (Baumrind, 1968, p. 261)

Baumrind's (1967, 1971a) operationalization of parenting style set her apart from earlier researchers in several ways. First, rather than determining with great exactitude multiple dimensions of parental behavior and defining style as a linear combination of these dimensions, Baumrind specified one broad parenting function-control-and added articulation within that single domain. Second, rather than demand that parental control be organized linearly from high to low (as was the implicit or explicit assumption of earlier theorists), she distinguished among three qualitatively different types of parental control: permissive, authoritarian, and authoritative. Third, Baumrind used a configurational approach to define parenting style, arguing that the influence of any one aspect of parenting (e.g., ideology, maturity demands, or the use of specific disciplinary techniques) is dependent on the configuration of all other aspects. In many ways, Baumrind's typology of parenting recalled the earliest conceptualizations of parenting style (e.g., Symonds, 1939 ), in that it described naturally occurring family niches organized around parents' belief systems.

The configurational approach was a natural outgrowth of Baumrind's initial interest in identifying and describing the parenting that was antecedent to clearly identified clusters of child behaviors (Baumrind, 1967; Baumrind \& Black, 1967). The configuration of practices associated with authoritative parenting reached beyond the issue of authority to include maturity demands, communication style (including both effectiveness and directionality), and nurturance (in which a distinction is made between warmth and involvement; Baumrind, 1965, 1967; Baumrind \& Black, 1967). Importantly, Baumrind found that parents who differ in the way they use authority also tend to differ along other dimensions, providing empirical as well as conceptual support for the configurational approach. For example, parents whose control practices warranted the label "permissive" or "authoritarian" were found also to make fewer maturity demands, communicate less effectively and more unilaterally, and act less nurturant and controlling than authoritative parents (Baumrind, 1967).

Baumrind's (1967) empirical validation of the configurational approach changed the emphasis of parenting style research and marked an important departure from the factor-analytic and circumplex traditions. Although in theory the authoritative-authoritarian-permissive typology was based solely on variations in patterns of parental authority, in reality the distinction was associated with other parenting attributes as well. For example, although Baumrind (1966) allowed conceptually that parents who use different styles of authority might be equally warm and loving, empirically she found that compared with authoritative parents, both authoritarian and permissive parents were similar in their relative detachment, the ineffectiveness of their communication skills, and their lower maturity demands (Baumrind, 1967). These results called into question the validity of searching for orthogonal dimensions of parenting, as earlier socialization researchers had done. Indeed, it became apparent that the advantage of a configurational approach grounded in naturally occurring parenting styles, rather than on theoretical dimensions alone, was its ecological validity.

Baumrind's (1967, 1971a) model also differed from those of earlier researchers in that it reflected what was then a paradigm shift in thinking about socialization-the emergence of the notion that children contribute to their own development through their influence on their parents. Although the possibility that temperamental differences in children might aiter parents' behaviors had been noted earlier (Baldwin, 1948), Baumrind (1989) explicitly tried to disentangle parent behaviors from child behaviors. For example, she measured parents' attempts to gain compliance independently of children's actual compliance (Baumrind, 1967, 1971a, 1971b). This allowed her to define parenting style as a characteristic of the parent, rather than of the parent-child relationship, a distinction that we, too, believe is crucial. Because earlier models had assumed that children were influenced by, but did not influence, their parents, previous operationalizations of parenting style had not addressed this distinction.

More important for the model we present in this review, Baumrind viewed the socialization process as dynamic; specifcally, she hypothesized that the parenting style used actually altered how open children are to their parents' attempts to socialize them. For example, she posited that authoritative parenting actually enhances the value of parental reinforcement and that authoritative parents' clear articulation of desired and proscribed behaviors enhances children's ability to discern correct responses to parental demands and enhances their cognitive ability (Baumrind, 1967). In essence, she suggested that authoritativeness increases the effectiveness of parenting by altering child characteristics that, in turn, strengthen the parents' ability to act as socialization agents.

Lewis's (1981) critique of Baumrind. Despite the apparent strengths of Baumrind's typological approach, an inherent disadvantage of any empirically derived typology is that the inevitable intercorrelation of different parent characteristics makes it difficult to discern the mechanism that underlies differences among children from different types of families. This problem was highlighted in Lewis's (1981) critique and reinterpretation of Baumrind's work. Lewis asked why strong external control such as that used by authoritative parents should induce children to internalize their parents' values, when attribution theory suggests that strong external controls should undermine internalization. In her reinterpretation of Baumrind's findings, Lewis suggested that it is not the high control characteristic of authoritative families that helps children develop an indepen- 
dent and autonomous sense of self while conforming to rules, but rather the reciprocal communication characteristic of authoritative families and the experience children in these families have of successfully modifying parental rules through argumentation. Specifically, Lewis suggested that Baumrind's findings could be reinterpreted as showing that the advantages enjoyed by authoritatively reared children are attributable to their parents' openness to bidirectional communication.

Lewis (1981) did not question the empirical validity of the association between authoritative parenting and child competence. In essence, however, she redefined authoritative parenting in terms of its emphasis on mutual accommodation rather than on a certain type of control. ${ }^{2}$ Although the validity of this redefinition remains an open question both empirically and conceptually, Lewis's reinterpretation brought into focus two important related points: (a) Any parenting typology (including Baumrind's) captures a configuration of parenting practices, thus making it difficult to ascertain what aspect of parenting affects which developmental outcomes, and (b) extant notions about the processes through which parenting style influences child development are speculative rather than empirically grounded.

The putative processes (e.g., mutual accommodation, effective conflict management, and firm control) by which parental authoritativeness might influence the development of competence have been discussed in depth, albeit hypothetically, by both Baumrind (1971a, 1983) and Lewis (1981). However, the configurational approach makes it difficult to move from the hypothetical to the empirical. This is especially true when comparisons are limited to comparisons of children raised in blatantly different parenting styles, because within-group studies would be necessary to specify the operative socialization processes. Unfortunately, the richness and detail of the data Baumrind gathered in her research necessarily restricted the size of the samples she studied, making the critical withingroup comparisons unfeasible.

In retrospect, a review of the Lewis-Baumrind argument underscores the fact that, despite consistent evidence that authoritative parents produce competent children, we still do not really know how or why. Both the attribution and social learning perspectives offer interesting hypotheses about the mechanisms through which such an association might come about, but the empirical evidence necessary to allow us to judge which hypotheses are correct is lacking.

\section{Maccoby and Martin's (1983) Two-Dimensional Framework}

Whatever its limitations, Baumrind's authoritative-authoritarian-permissive typology proved a fruitful focus for research on parenting. By the early $1980 \mathrm{~s}$, this tripartite model was firmly established in the field of child development and served as the organizing heuristic for most discussions of parents' influence on their children's development. However, although Baumrind specifically limited the scope of her investigation to the influence of parenting variations within well-functioning families, other researchers were interested in a broader range. In an influential review published in the Handbook of Child Psychology, Maccoby and Martin (1983) attempted to merge
Baumrind's configurational approach with earlier attempts to define parenting along a limited number of dimensions. They did so by attempting to capture parenting style as a function of two dimensions, which they labeled responsiveness and demandingness.

Maccoby and Martin's (1983) transformation of Baumrind's configurational typology facilitated investigations of the generalizability of Baumrind's model to populations quite different from the one in which the typology arose, by creating linear constructs along which theoretically important aspects of parenting could be measured. For both Baumrind (1983) and Maccoby and Martin (1983), parenting style was best understood within a social learning or ethological perspective. Parenting style was defined as reflecting two specific underlying processes: (a) the number and type of demands made by the parents and (b) the contingency of parental reinforcement. Authoritative parents are high in both demandingness and responsiveness. Authoritarian parents are high in demandingness but low in responsiveness. Whereas empirically, Baumrind had found the "permissive" type, Maccoby and Martin distinguished two distinct patterns of parenting. In their framework, indulgent parents are defined as high in responsiveness but low in demandingness. Neglecting parents are defined as low in both responsiveness and demandingness. The neglecting pattern arises both logically, as a consequence of crossing the two theoretical dimensions (i.e., responsiveness and demandingness), and ecologically, because doing so includes a broader range of parenting than had been represented in Baumrind's earlier sample of mainly conscientious parents.

In earlier models of socialization based on two orthogonal dimensions of parenting, warmth or an attribute similar to warmth (e.g., acceptance, love, etc.) was always one of the critical dimensions. In Maccoby and Martin's (1983) model, however, the contingency of parent and child behavior replaced warmth as an organizing element:

\begin{abstract}
Whether parental responsiveness be viewed as contingent reinforcement (meaning, presumably, that the parents are "shaping" the child by responding differentially to desired and undesired behavior), as providing control to the child, or merely as parental sensitivity and adaptation to the child's signals, states, and needs, the concept differs importantly from that of warmth, which includes affection or praise when they are contingently but also when they are given on the parent's impulse regardless of the concurrent state, signals, and behavior of the child. (p. 39)
\end{abstract}

In her more recent work (1978, 1980, 199la, 1991b), Baumrind has used the concepts of responsiveness and demandingness to reflect the balance of demands between society (as reflected through the parent) and the individual. She has written,

\footnotetext{
${ }^{2}$ More recently, Baumrind (1983) has written that "differences among authoritative, permissive, and authoritarian families should be attributed to contrasting styles of managing parent-child disciplinary conflict" (p. 138; also see Cooper, 1988). In some respects, this appears to be a restatement of the typology's conceptual derivation. However, although the typology originally was defined according to stylistic differences in parents' orientation toward their socialization duties (i.e., toward control), it actually was operationalized in terms of the management of conflict.
} 
Demandingness refers to the claims parents make on the child to become integrated into the family whole by their maturity demands, supervision, disciplinary efforts and willingness to confront the child who disobeys. Responsiveness refers to actions which intentionally foster individuality, self-regulation and selfassertion by being attuned, supportive and acquiescent to the child's special needs and demands. (1991a, p. 748)

In other words, demandingness refers to the parent's willingness to act as a socializing agent, whereas responsiveness refers to the parent's recognition of the child's individuality. Thus the two dimensions reflect two types of demands: those made by the society on the child (as conveyed through the parent) and those made by the child on society. Baumrind (1978) cogently laid out this balance in her discussion of how authoritative parents instill instrumental competence by helping their children balance other-oriented, rule-following tendencies with individualistic, autonomous, active thinking.

Although the authoritarian and authoritative parenting styles defined by responsiveness and demandingness have familiar names, they only approximate, and do not directly correspond to, the patterns described by Baumrind. For example, Maccoby and Martin (1983) explicitly separated their discussion of parental communication patterns from their discussion of parenting style, although reciprocity of communication and use of explanations and reasoning are important characteristics that Baumrind said distinguished authoritative from authoritarian parents. Differences in the quality of control between authoritative and authoritarian parents may not be captured in models that rely solely on the measurement of responsiveness and demandingness, because they do not include assessments of other important distinguishing features, such as restrictiveness, autonomy granting, warmth, and coerciveness.

As Maccoby and Martin (1983) noted, defining configurational typologies using linear dimensions can prove a Procrustean bed for empirical typologies and may lead to subtle difficulties in interpretation. It is tempting, for example, to describe differences in the development of the children of authoritative and authoritarian parents as resulting from differences in parental responsiveness because in Maccoby and Martin's typology both styles of parenting are defined as high in demandingness. In contrast, although Baumrind (1989) described both authoritative and authoritarian parents as demanding, the quality of their demandingness is different, above and beyond the differences ascribed to responsiveness. In fact, Baumrind distinguished two aspects of demandingness: restrictiveness (similar to what others [e.g., Schaefer, 1965; Steinberg et al., 1989] have called psychological control) and firm control (similar to what others [e.g., Steinberg et al., 1989] have called behavioral control). Both authoritative and authoritarian parents are high in firm control, but only authoritarian parents are highly restrictive (i.e., high in psychological control).

The move by Maccoby and Martin (1983) away from the configurational approach toward one that defined configurations on the basis of orthogonal dimensions marked an attempt-reminiscent of earlier attempts to differentiate underlying dimensions of parenting style - to tease apart the processes that underlie the influence of style. By 1983, qualitatively different types of parental authority had been transformed back into a framework based on quantitative differences measured along two dimensions.

\section{Style as Context: An Integrative Model}

We noted earlier that past models of parenting have identified three characteristics of parents that determine the processes through which parenting style influences child development: the values and goals parents have in socializing their children, the parenting practices they employ, and the attitudes they express toward their children. We have argued that a very real tension has existed in the literature between building typologies of parenting style to capture the parenting milieu, or gestalt, and attempting to understand the mechanisms through which style influences child development by disaggregating parenting style into its component parts. If we are to move beyond a "family address" model of parenting and understand the processes through which parenting style influences children, models of parenting style must account for the crucial mediating processes. In the previous section, we discussed the elements of such a model in historical context. In this section, we suggest how these elements fit together as a whole. In articulating such a model, we focus our attention on processes that occur within the family setting. We recognize, of course, that such processes may (and probably do) vary as a function of other influences outside the immediate setting, such as the family's culture, class, or composition.

Researchers from Symonds (1939) to Dornbusch et al. (1987) have argued that the values parents hold and the goals toward which they socialize their children are critical determinants of parenting behavior. These socialization goals include both the child's acquisition of specific skills and behaviors (e.g., appropriate manners, social skills, and academic ability) and the child's development of more global qualities (e.g., curiosity, critical thinking, independence, spirituality, and the capacity to experience joy or love). Although these goals and values have a direct affect on parenting behavior, it is only through parenting behavior that these goals can influence the developing child (Becker, 1964). We propose that the attributes of parenting influenced by these goals are of at least two distinct types: parenting practices and parenting style. Moreover, we argue that in order to understand the processes through which parents influence their children's development, researchers must maintain this distinction between practice and style.

Parenting practices are behaviors defined by specific content and socialization goals. Attending school functions and spanking are both examples of parenting practices. Depending on the hypothesized relationship between a socialization goal and a child outcome, practices may be operationalized at different levels. For example, if one were interested in the development of adolescent self-esteem, one might hypothesize that the children of parents who showed interest in their child's activities would develop more positive self-esteem than would children whose parents did not. In such a case, it would make sense to equate such diverse parental behaviors as attending baseball games or school functions, asking about the child's friends, and going to art museums at the child's request as different manifestations of the same basic practice. If the socialization goal is school achievement and the hypothesized process of influence 
is communicating the importance of academics, parenting practices such as making time for the child to do homework, attending school functions, and inquiring about grades might all be considered equivalent. Parenting practices are best understood as operating in fairly circumscribed socialization domains, such as academic achievement, independence, or cooperation with peers. Depending on the specific developmental outcome of interest, different parenting practices would be more or less important to investigate.

A second class of parenting attributes influenced by parents' goals and values is parenting style. Earlier, we defined parenting style as a constellation of attitudes toward the child that are communicated to the child and create an emotional climate in which the parent's behaviors are expressed. These behaviors include aspects of the behaviors that encompass parenting practices as well as other aspects of parent-child interaction that communicate emotional attitude but are not goal directed or goal defined: tone of voice, body language, inattention, bursts of temper, and so on. Thus, global parenting style is expressed partly through parenting practices, because these are some of the behaviors from which children infer the emotional attitudes of their parents. Parenting style is not simply a more distal variable mediated through proximal parenting practices, however.

Using Baumrind's (1971a) prototype of an authoritative parent as an example of a parenting style, we note two ways in which the concept differs from that of parenting practice. First, unlike our descriptions of parenting practice, the description of the authoritative style is independent of the content of the parenting behavior. Thus, an authoritative mother encourages verbal give-and-take and shares with the child the reasoning behind her policies, but her authoritativeness is independent of the content of her socialization. For example, one authoritative parent might have a policy stating that homework must be finished before the child engages in any other activity, whereas another might require outdoor exercise before homework is tackled. Thus, in our model, parenting style differs from parenting practices in that it describes parent-child interactions across a wide range of situations, whereas practices are by definition domain specific.

Second, because parenting style is theoretically independent of specific socialization content, and because a style is displayed across a range of parent-child interactions, parenting style conveys to the child the parent's attitude toward the child, rather than toward the child's behavior. To return once again to Baumrind's framework, the authoritative mother communicates her authority to the child through her comfort in asserting her influence; she communicates her recognition of the child's separateness and capacity to understand through her explanations; and she communicates her respect for the child through her reluctance to assert her will superfluously.

In the model we propose, both parenting style and parenting practices result in part from the goals and values parents hold (Figure 1, Arrows 1 and 2). Yet we posit that each of these parenting attributes influences the child's development through different processes. Parenting practices have a direct effect on the development of specific child behaviors (from table manners to academic performance) and characteristics (such as acquisition of particular values, or high self-esteem). In essence, parenting

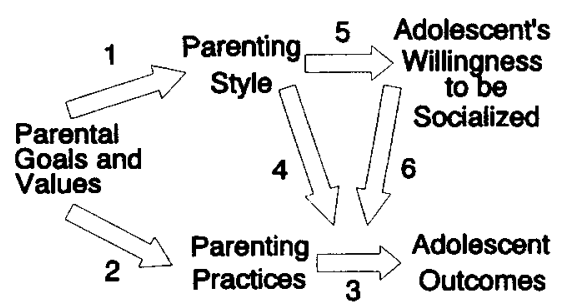

Figure 1. Contextual model of parenting style. Parenting goals for socialization influence both parenting style (Arrow 1) and parenting practices (Arrow 2). Parenting practices have a direct effect on specific child developmental outcomes (Arrow 3). In contrast, parenting style influences child development primarily through its moderating influence on the relationship between parenting practices and developmental outcomes (Arrow 4) and through its influence on the child's openness to parental socialization (Arrow 5). The child's openness to socialization also moderates the influence of parenting practice on the child's development (Arrow 6).

practices are the mechanisms through which parents directly help their child attain their socialization goals (Figure 1, Arrow 3). In contrast (and in contradistinction to previous authors), the primary processes through which parenting style influences child development are indirect. Parenting style alters the parents' capacity to socialize their children by changing the effectiveness of their parenting practices. From this perspective, parenting style can best be thought of as a contextual variable that moderates the relationship between specific parenting practices and specific developmental outcomes.

We hypothesize that parenting style moderates the influence of parenting practices on the child's development in at least two ways: by transforming the nature of the parent-child interaction, and thus moderating the specific practices' influence on child outcomes (Figure 1, Arrow 4), and by influencing the child's personality, especially the child's openness to parental influence (Figure 1, Arrow 5). This openness to socialization on the part of child in turn moderates the association between parenting practices and child outcome (Figure 1, Arrow 6).

For example, it is widely reported that adolescent school performance is enhanced by parental involvement in the child's schooling (e.g., Stevenson \& Baker, 1987). In a recent examination of this assertion, however, we have shown that the effectiveness of parents' school involvement in facilitating adolescent academic achievement is greater among authoritative than nonauthoritative parents (Steinberg, Lamborn, Dornbusch, \& Darling, 1992), that is, the magnitude of the correlation between school involvement and academic performance varies as a function of the level of parental authoritativeness in the parent-child relationship generally. One might speculate that authoritative parents are more effective during school-related interactions with the child, such as helping the adolescent choose courses, because their use of explanations, their encouragement of discussion, and their acknowledgement of the adolescent's perspective help the adolescent make more intelligent decisions. This is an example of how style may enhance the effectiveness of a specific parenting practice, making it a better practice than it would be in a different stylistic context (Figure 1, Arrow 4). 
In addition, authoritativeness may enhance the effectiveness of a practice through its influence on the child's openness to socialization, for example, by increasing the child's desire to make his or her parents proud in a domain known to be important to them (Figure 1, Arrow 5). Thus, authoritative parents' involvement in school activities may communicate the importance they place on academics to an adolescent who is already receptive to parental values, thus enhancing the impact of involvement (Figure 1, Arrow 6). Conversely, authoritarian parenting may increase adolescents' resistance to parental advice, and this resistance might attenuate the otherwise beneficial effects of involvement.

Although both types of processes (increasing the effectiveness of parents' attempts to guide children and enhancing children's openness to guidance) have been discussed with regard to parenting style (e.g., Baumrind, 1967), earlier models have failed to distinguish between the style of the socializing agent (e.g., the parent), the goals toward which socialization is directed, or the means through which parents attempt to socialize their children. This confounding is particularly problematic when one attempts to interpret the results of parenting style research.

For example, the assumption that underlies comparisons of the academic performance of authoritatively and nonauthoritatively reared children is that the differences between them can be attributed solely to stylistic differences. In other words, it might be argued that adolescents from authoritative families perform better than their peers from nonauthoritative families solely because of their parents' emotional supportiveness and high standards (if authoritativeness were so defined). Such an interpretation ignores the possibility that authoritative and nonauthoritative parents may also differ in the goals toward which they direct their children or the methods they use to help their children reach those goals. For example, although most parents hope that their children will excel academically, authoritative, permissive, and authoritarian parents may differ in the relative importance they place on the goals of academic excellence and social success or in the ways in which they help their children succeed.

Although previous researchers have recognized this dilemma either in their explicit conceptualization of parenting style as a combination of all these elements (e.g., Baumrind, 1967) or in their explanations of why the influence of parenting style varies from one group to the next (i.e., Dornbusch et al., 1987), the dilemma must be not only recognized but also resolved in order to move toward an understanding of process. It is to this problem that we address our model.

Concretely, we postulate that the extent to which children manifest a particular psychological or behavioral characteristic varies as a joint function of (a) the extent to which the practices the parents use are correlated with that specific outcome and (b) the extent to which the style the parents use is effective in influencing the child in general. Accordingly, predictions about the consequences of various socialization techniques must take into account both style and practice. For example, we would hypothesize that the children of authoritative parents who emphasize school performance through their parental practices will perform better in school than will the children of nonauthoritative parents whose education-specific practices are iden- tical. At the same time, we would also hypothesize that children of authoritative parents who do not emphasize academic performance will perform worse in school than will authoritatively reared youngsters whose parents' practices emphasize achievement.

\section{Directions for Future Socialization Research}

The conceptual distinction we offer between parenting practices and parenting style both advances the study of socialization in the family and facilitates the examination of three unresolved issues in the study of familial influences on child development: First, how does the influence of parenting style vary as a function of the cultural background of the developing person? Second, what are the processes through which parenting style influences child development? Third, what are the determinants of parenting style? In this section, we briefly discuss each of these issues.

Contextual variability. An important question raised in the recent work that has expanded socialization research beyond White, middle-class samples is whether and why the influence of parenting style and practices varies across cultural contexts. For example, both Dornbusch et al. (1987) and Steinberg et al. (1991), using different approaches to the measurement of authoritative parenting, have found that the association between authoritativeness and school performance is much stronger among European- and Hispanic-American adolescents than among Asian- and African-American adolescents. Many hypotheses have been offered for this difference, including countervailing peer or community influences, social disincentives for academic success, and the relative functionalism of academic success for youths from different ethnic backgrounds (Steinberg, Dornbusch, \& Brown, 1992). An additional hypothesis, however, concerns differences in the goals toward which parents socialize their children. It is possible that authoritative parenting as a style is equally effective in socializing children across all cultural contexts, but that the goals toward which children are socialized, and thus parents' practices, vary across these very same ecologies (Baumrind, 1971a). Before concluding that authoritative parenting, or, for that matter, any other style of parenting, is more or less effective in different cultural contexts, we need to know more about the goals toward which parents socialize their children and the practices they use to achieve these goals.

Processes of influence. Despite many years of research, we know surprisingly little about the processes through which parenting style influences the development of children's competence. Although the implicit processes proposed have nearly always included changes in characteristics of the child (presumably through modeling or changes in cognitive complexity, attributions, or the emotional relationship with the parent), research documenting these processes is scant. In one exception to this general trend, Steinberg et al. (1989) found that the relationship between parenting style and adolescents' academic performance was mediated specifically through changes in adolescent psychosocial maturity. More research is needed that specifies both the discrete aspects of parenting style that influence changes in child characteristics and how these changes mediate the relationship between style and behavioral outcome. This 
kind of basic research would provide insight, for example, into such questions as whether the difference between patterns of drug use in the adolescents of authoritative parents and democratic parents (i.e., warm parents who do not assert their authority as clearly as do authoritative parents; Baumrind, 1989) result from differences in the adolescents' desire for parental approval, differences in the contingency of parental approval visà-vis the adolescent's behavior, differences in the type of peers with whom children from different types of families associate, or other processes entirely.

We believe that a focus on the processes that link parenting style and parenting practices to child outcomes would also facilitate a more developmental approach to the study of socialization. Although it is obvious that the meaning and effects of parenting practices change with the child's age (e.g., the type of monitoring necessary to ensure a toddler's safety is developmentally inappropriate for an adolescent), it is unclear how the influences of parenting style and practices change across the life course. We know little about such important questions as the stability of parenting style across time, the influence of changes in parenting style on children (e.g., sudden decreases or increases in parental autonomy granting), or the relative advantages and disadvantages of different aspects of parenting style during different developmental periods. As a case in point, Steinberg et al. (1989) argued that psychological autonomy granting may be a particularly important component of parenting style during adolescence. Although this argument is plausible, there are little data bearing on questions of how the importance of psychological autonomy granting, or any other aspect of parenting style, changes from infancy through adolescence.

Antecedents of parenting style. Equally little is known about why parents adopt different parenting styles. Within the family, possible influences include the values parents hold and the goals toward which they try to socialize their children, the parents' emotional and material resources, and both the parents' and child's personalities (Belsky, 1984). One advantage of disentangling parenting practice from parenting style is that it facilitates looking at variability in parenting style both within and across families. For example, this strategy allows researchers to examine the influence of child characteristics on parenting style within families for children of different ages. Outside the family, cultural differences in normative parenting practices may also contribute to stylistic variability. The prevalence of different styles of parenting varies markedly among ethnic groups in contemporary America (Steinberg, Lamborn, Dornbusch, \& Darling, 1992) and from one historical period to the next (Bronfenbrenner, 1985). Maintaining the distinction between style and practice will facilitate investigations of the sources of this sociocultural variability.

\section{Conclusion}

In 1954, Child wrote, "It is probable that the combined study of general parental characteristics and specific features of socialization as joint antecedent variables will be one of the important directions taken by future research" (p. 688). In our estimation, little about Child's prescient statement warrants modification, nearly 4 decades after it was first written. Viewing parenting style as a context that facilitates or undermines parents' efforts to socialize their children may hold the greatest promise for future research on familial influences on child and adolescent development. Because parenting style is best understood as a context within which socialization occurs, rather than as a socialization practice itself, careful investigations of how the effectiveness of specific parenting practices varies as a function of this context must be conducted.

\section{References}

Baldwin, A. L. (1948). Socialization and the parent-child relationship. Child Development, 19, 127-136.

Baldwin, A. L. (1955). Behavior and development in childhood. New York: Dryden Press.

Baumrind, D. (1965). Parental control and parental love. Children, 12, 230-234.

Baumrind, D. (1966). Effects of authoritative control on child behavior. Child Development, 37, 887-907.

Baumrind, D. (1967). Child care practices anteceding three patterns of preschool behavior. Genetic Psychology Monographs, 75, 43-88.

Baumrind, D. (1968). Authoritarian v. authoritative parental control. Adolescence, 3, 255-272.

Baumrind, D. (1970). Socialization and instrumental competence in young children. Young Children, 26, 104-119.

Baumrind, D. (1971a). Current patterns of parental authority. Developmental Psychology Monograph, 4 (1, Pt. 2).

Baumrind, D. (1971b). Harmonious parents and their preschool children. Developmental Psychology, 4, 99-102.

Baumrind, D. (1972). An exploratory study of socialization effects on Black children: some Black-White comparisons. Child Development, 43, 261-267.

Baumrind, D. (1978). Parental disciplinary patterns and social competence in children. Youth and Society, 9, 239-276.

Baumrind, D. (1980). New directions in socialization research. American Psychologist, 35, 639-652.

Baumrind, D. (1983). Rejoinder to Lewis's reinterpretation of parental firm control effects: Are authoritative families really harmonious? Psychological Bulletin, 94, 132-142.

Baumrind, D. (1989). Rearing competent children. In W. Damon (Ed), Child development today and tomorrow (pp. 349-378). San Francisco: Jossey-Bass.

Baumrind, D. (1991a). Parenting styles and adolescent development. In J. Brooks-Gunn, R. Lerner, \& A. C. Petersen (Eds.), The encyclopedia of adolescence (pp. 746-758). New York: Garland.

Baumrind, D. (1991b). Types of middle-class adolescent substance users: Concurrent family and personality influences. Unpublished manuscript, Institute of Human Development, University of California, Berkeley.

Baumrind, D., \& Black, A. E. (1967). Socialization practices associated with dimensions of competence in preschool boys and girls. Child Development, 38, 291-327.

Becker, W. C. (1964). Consequences of different kinds of parental discipline. In M. L. Hoffman \& L. W. Hoffman (Eds.), Review of child development research (Vol. 1, pp. 169-208). New York: Russell Sage Foundation.

Belsky, J. (1984). The determinants of parenting: A process model. Child Development, 55, 83-96.

Bronfenbrenner, U. (1958). Socialization and social class through time and space. In E. E. Maccoby, T. M. Newcomb, \& E. L. Hartley (Eds.), Readings in social psychology (pp. 400-425). New York: Holt, Rinehart \& Winston.

Bronfenbrenner, U. (1961a). Some familial antecedents of responsibility and leadership in adolescents. In L. Petrullo \& B. M. Bass (Eds.), Leadership and interpersonal behavior (pp. 239-271). New York: Holt, Rinehart \& Winston. 
Bronfenbrenner, U.(1961b). The changing American child-A speculative analysis. Merrill-Palmer Quarterly of Behavior and Development, 7, 73-84.

Bronfenbrenner, U. (1985). Freedom and discipline across the decades. In G. Becker, H. Becker, \& L. Huber (Eds.), Sonderdrucke aus: Ordnung und Unordnung (pp. 326-339). Berlin, Federal Republic of Germany: Beltz Verlag, Weinheim, und Basel.

Child, I. L. (1954). Socialization. In G. Lindzey (Ed.), Handbook of social psychology (Vol. 2, pp. 655-692). Reading, MA: AddisonWesley.

Cooper, C. (1988). Commentary: The role of conflict in adolescent parent relationships. In M. Gunnar (Ed.), 21st Minnesota symposium on child psychology (pp. 181-187). Hillsdale, NJ: Erlbaum.

Dornbusch, S. M., Ritter, P. L., Leiderman, P. H., Roberts, D. F., \& Fraleigh, M. J. (1987). The relation of parenting style to adolescent school performance. Child Development, 58, 1244-1257.

Freud, S. (1933). New introductorylectures in psychoanalysis. New York: Norton.

Kohn, M. L. (1969). Class and conformity: A study in values. Homewood, IL: Dorsey Press.

Lewis, C. C. (1981). The effects of parental firm control: A reinterpretation of the findings. Psychological Bulletin, 90, 547-563.

Maccoby, E. E., \& Martin, J. A. (1983). Socialization in the context of the family: Parent-child interaction. In P. H. Mussen (Series Ed.) \& E. M. Hetherington (Vol. Ed.), Handbook of child psychology: Vol. 4. Socialization, personality, and social development (4th ed., pp. 1-101) New York: Wiley.

Orlansky, H. (1949). Infant care and personality. Psychological Bulletin, $46,1-48$

Parsons, T., \& Bales, R. F. (1955). Family, socialization and interaction process. New York: Free Press of Glencoe.

Rogers, C. R. (1960). A therapist's view of personal goals (Pendle Hill Pamphlet No. 108). Wallingford, PA: Pendle Hill.

Schaefer, E. S. (1959). A circumplex model for maternal behavior. Journal of Abnormal and Social Psychology, 59. 226-235.
Schaefer, E. S. (1965). Children's reports of parental behavior: An inventory. Child Development, 36, 413-424.

Schaefer, E., \& Bell, R. (1958). Development of a parental attitude research instrument. Child Development, 29, 339-361.

Sears, R. R. (1957). Identification as a form of behavior development In D. B. Harris (Ed), The concept of development (pp. 149-161). Minneapolis: University of Minnesota Press.

Sears, R. R., Maccoby, E., \& Levin, H. (1957). Patterns of child rearing. Evanston, IL: Row, Peterson.

Steinberg, L., Dornbusch, S., \& Brown, B. (1992). Ethnic differences in adolescent achievement: An ecological perspective. American Psychologist, 47, 723-729.

Steinberg, L., Elmen, J. D., \& Mounts, N. S. (1989). Authoritative parenting, psychosocial maturity, and academic success among adolescents. Child Development, 60, 1424-1436.

Steinberg, L., Lamborn, S., Dornbusch, S., \& Darling, N. (1992). Impact of parenting practices on adolescent achievement: Authoritative parenting, school involvement, and encouragement to succeed. Child Development, 63, 1266-1281.

Steinberg, L., Mounts, N. S., Lamborn, S. D., \& Dornbusch, S. M (1991). Authoritative parenting and adolescent adjustment across varied ecological niches. Journal of Research on Adolescence, 1,1936.

Stevenson, D., \& Baker, D. (1987). The family-school relation and the child's school performance. Child Development, 58, 1348-1357.

Symonds, P. M. (1939). The psychology of parent-child relationships New York: Appleton-Century-Crofts.

Watson, J. B. (1928). Psychological care of infant and child. New York: Norton.

Whiting, J. W. M., \& Child, I. L. (1953). Child training and personality: A cross-cultural study: New Haven, CT: Yale University Press.

Received June 4, 1991

Revision received July 21,1992

Accepted July 27, 1992 